\title{
Décadrages Décadrages
}

cinéma, à travers champs Cinéma, à travers champs

13 | 2008

Anna Sanders Films, cinéma et art contemporain

\section{Ciobanul Zburator : la fiction se met au service du documentaire}

Valère Gogniat

\section{OpenEdition}

1 Journals

Édition électronique

URL : https://journals.openedition.org/decadrages/537

DOI : $10.4000 /$ decadrages. 537

ISSN : 2297-5977

Éditeur

Association Décadrages

Édition imprimée

Date de publication : 10 octobre 2008

Pagination : 112-114

ISBN : 978-2-9700582-8-1

ISSN : 2235-7823

\section{Référence électronique}

Valère Gogniat, "Ciobanul Zburator : la fiction se met au service du documentaire », Décadrages [En ligne], 13 | 2008, mis en ligne le 10 octobre 2009, consulté le 03 avril 2022. URL : http://

journals.openedition.org/decadrages/537; DOI : https://doi.org/10.4000/decadrages.537

Ce document a été généré automatiquement le 3 avril 2022.

( Décadrages 


\title{
Ciobanul Zburator : la fiction se met au service du documentaire
}

\author{
Valère Gogniat
}

1 Catalin Musat, jeune réalisateur roumain, s'exerce ici à la réalisation d'un court métrage à double tranchant. Auteur de plusieurs petits films de fiction et documentaires, il décide pour Ciobanul Zburator (Le berger volant) de mêler ces deux «genres » avec un résultat plutôt convaincant. En utilisant presque exclusivement des plans fixes, Musat dresse le portrait de cinq bergers roumains, isolés dans une campagne dont on n'arrive que très mal à mesurer l'étendue. Ce n'est qu'au fil des plans que l'on découvre que leurs terres bordent la piste d'atterrissage d'un aéroclub allemand. Dès cet instant, ils ne retrouveront plus leur tranquillité, incessamment dérangés par les vrombissements des ULM germaniques (Ultra Légers Motorisés, petits engins bruyants volant à basse altitude, rappelant les nombreuses mouches qui bruissent continuellement autour des bergers). Finalement, après d'innombrables vols des machines au-dessus des têtes des pauvres hommes, l'un d'eux se décide à prendre place à l'arrière de l'un de ces engins, et ne reviendra plus.

2 L'aspect le plus intéressant de cette fable souvent poétique est sans conteste l'entremêlement de la fiction et du documentaire. Musat utilise ici un argument fictionnel (le litige avec le petit aéroclub) pour souligner des éléments bien réels de la vie de ces bergers. Leur pauvreté, l'absence de loisirs, la stagnation de leur situation sociale (pas de possibilité de "décoller») ou les problèmes que peut rencontrer la Roumanie à côtoyer l'Union Européenne : autant d'amers constats que le réalisateur relate, non pas grâce à une classique voix over (telle qu'on pourrait en trouver dans certains documentaires didactiques), mais par l'utilisation subtile d'éléments fictionnels. Le court métrage suit un régime intéressant, oscillant sans cesse entre monstration et narration : tantôt de silencieux plans fixes dépeignent l'environnement des bergers, tantôt une mise en scène tragi-comique illustre leur relation aux pilotes allemands. L'utilisation dans ce film d'éléments fictionnels à des fins exclusivement métaphoriques nous a surpris et c'est sur ce point que nous voudrions nous arrêter. 
3 Il convient de dire quelques mots de cet aspect « documentaire » que l'on retrouve à de nombreux niveaux dans le film. Relevons d'abord la bande sonore intégralement intradiégétique et comportant de très nombreux et longs silences. Cette sobriété nous aide à comprendre que le réalisateur ne veut pas imposer un sens ou une atmosphère mais témoigner simplement de cette réalité. Mentionnons ensuite les nombreux plans qui n'ont pas d'utilité au niveau fictionnel mais qui rendent compte de l'environnement direct de la bergerie (la séquence de l'orage, par exemple, où les plans successifs montrant l'éclair, l'envol de la nuée d'oiseaux, l'herbe subissant les assauts de la grêle ou les gouttes d'eau suspendues à la gouttière ne sont finalement que purement descriptifs). Il faut encore relever les plans larges sur l'ensemble de la bergerie. Toujours sans lien direct avec le conflit opposant les bergers aux Allemands, ces plans ont pour seul but la présentation du mode de vie des bergers en Roumanie. Bergers qui ne sont pas toujours à la disposition du metteur en scène. Preuve en est un très léger panoramique qui rompt la succession de plans fixes pour ajuster le cadrage sur l'un des bergers en train de sortir du champ. Il en témoigne bien : certains plans sont pris «sur le vif ».

4 Ce n'est bien sûr pas le cas de ceux qui servent l'aspect fictionnel du court métrage. Certains segments sont intégralement construits par le réalisateur pour produire un sens métaphorique. On pense par exemple à une séquence de repas où deux bergers mangent tranquillement dans leur cabane quand le vacarme d'un ULM les attire à l'extérieur. Ils sortent afin de découvrir ce qui peut provoquer un tel bruit. S'ensuit un certain nombre de champs/contrechamps montrant successivement l'engin survolant la bergerie et l'air dubitatif des bergers. Cette séquence en dit beaucoup sur la situation de ces hommes. Plaqués au ras du sol de l'échelle sociale, condamnés à s'ennuyer ferme en assistant aux loisirs des autres et prisonniers de leur condition, ils doivent subir l'affront involontaire des Allemands qui prennent du plaisir juste au-dessus de leur nez, et retourner s'occuper de leurs moutons sans broncher. Occasionnellement, la mise en scène constitue également un moyen pour métaphoriser les sujets qui paraissent chers aux yeux du réalisateur. Prenons par exemple l'un des derniers plans, où le berger décide d'aller prendre place sur un ULM et de quitter son univers. Ici, la construction du plan est saisissante: les moutons, masse blanche compacte, au premier plan, le berger qui marche en direction de l'arrière-plan pour rejoindre l'ULM au deuxième plan, et finalement, au fond, la route et les voitures qui circulent. Le plan est bien plus éloquent que n'importe quelle voix over relatant comment le berger peut, au prix de l'abandon de ses moutons, quitter le monde dans lequel il semble cloîtré et rejoindre la civilisation, source ici de loisirs et de vie facile (vision très manichéenne des choses, reconnaissons-le). Dans ce film, il n'y a donc que très peu d'informations passant par le verbal, mais Musat montre qu'il connait d'autres moyens de discourir sur les sujets qui l'intéressent.

5 Ce court métrage remplit ainsi son contrat et saura ravir les spectateurs. Malgré certaines difficultés (je pense aux séquences où l'on demande aux bergers de jouer leur rôle, chose qui leur est impossible à voir les multiples regards-caméras visiblement involontaires), le pari de Musat est réussi. Sans aucun doute, c'est l'un des court métrages qui est sorti du lot durant cette compétition tessinoise.

Ciobanul Zburator (The Flying Sheperd, Roumanie, 2008, 26')

Réalisation et scénario : Catalin Musat 
Image : Marius Iacob

Montage : Vlad Voinescu 